\title{
Salvage endoscopic submucosal dissection for recurrent invasive Barrett neoplasia after endoscopic resection and radiofrequency ablation
}

Endoscopic resection is indicated for visible lesions in Barrett's esophagus (BE) for either curative treatment or optimal histopathological staging [1]. Endoscopic submucosal dissection (ESD) should be considered only for lesions larger than $15 \mathrm{~mm}$ [2]. Even in larger lesions, it still offers a moderate rate of cure [3].

We report the case of an 82 -year-old man with a $40 \times 30-\mathrm{mm}$ visible lesion in an area of $\mathrm{BE}(\mathrm{C} 8 \mathrm{M} 8)$, which was removed R0 by ESD, with the histological diagnosis being high grade dysplasia (\Fig.1). Subsequent high definition endoscopy found no suspicious visible lesions. Radiofrequency ablation (RFA) was scheduled for the remaining $B E$. However, on the second session of RFA, two suspicious lesions were detected and biopsies confirmed the presence of an adenocarcinoma component within high grade dysplasia. It was decided to perform salvage endoscopic resection to manage these recurrent lesions.

We performed ESD with the "tunnel+ clip" strategy [4] (\$ Fig.2). In spite of severe fibrosis, we were able to remove the lesions endoscopically en bloc, without any adverse events, in 1 hour ( Video 1). Two specimens measuring $55 \times 40 \mathrm{~mm}$ and $12 \times 10 \mathrm{~mm}$ were submitted for pathological analysis, which confirmed an $\mathrm{R} 0$ resection of moderately differentiated adenocarcinoma with budding and submucosal invasion less $200 \mu \mathrm{m}$ (pT1b) (Lesion \#1) and an intramucosal adenocarcinoma (Lesion \#2) ( Fig.3). A shared discussion of the choice between salvage surgery and endoscopic surveillance took place with the patient.

This is the first case reported so far of recurrent invasive BE neoplasia within a period of only 7 months from the initial curative endoscopic resection. Regardless of severe fibrosis following the previous resection and RFA, complete resection by endoscopy remained feasible and safe with the "tunnel + clip" strategy.

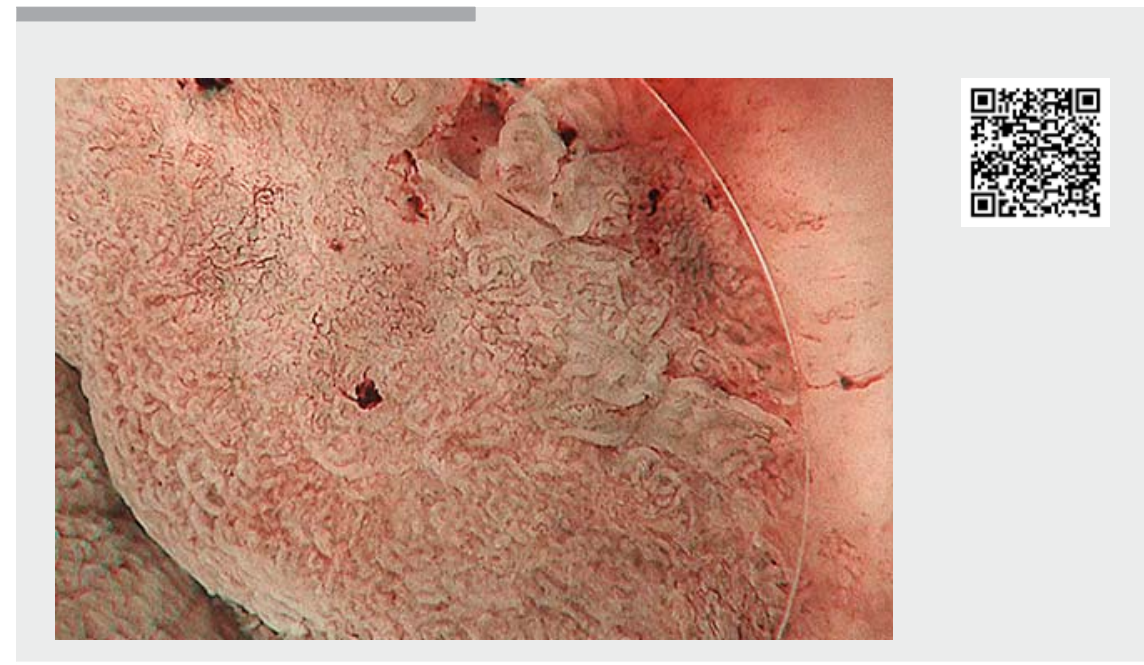

Video 1 An initial high grade dysplastic lesion in an area of Barrett's esophagus (BE) is resected by endoscopic submucosal dissection (ESD), with subsequent radiofrequency ablation (RFA) of the remaining BE. Two recurrent lesions identified 7 months later are successfully treated by ESD with the "tunnel + clip" strategy despite severe fibrosis.
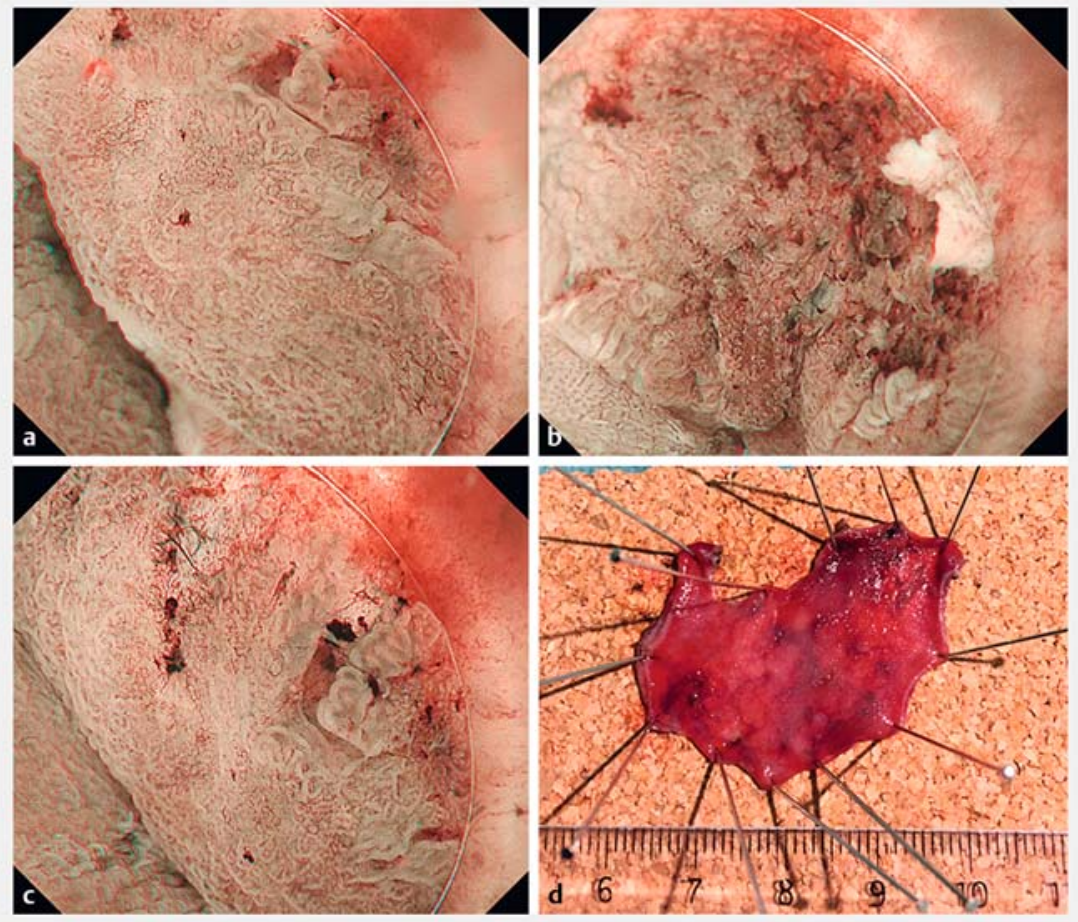

Fig. 1 Endoscopic views of the initial high grade dysplastic lesion in an area of Barrett's esophagus (C8M8) on: a high definition endoscopic examination; b examination with acetic acid and narrow-band imaging (NBI) with magnification; c examination with NBI with magnification. $\mathbf{d}$ The $40 \times 30-\mathrm{mm}$ specimen that was resected by endoscopic submucosal dissection. 

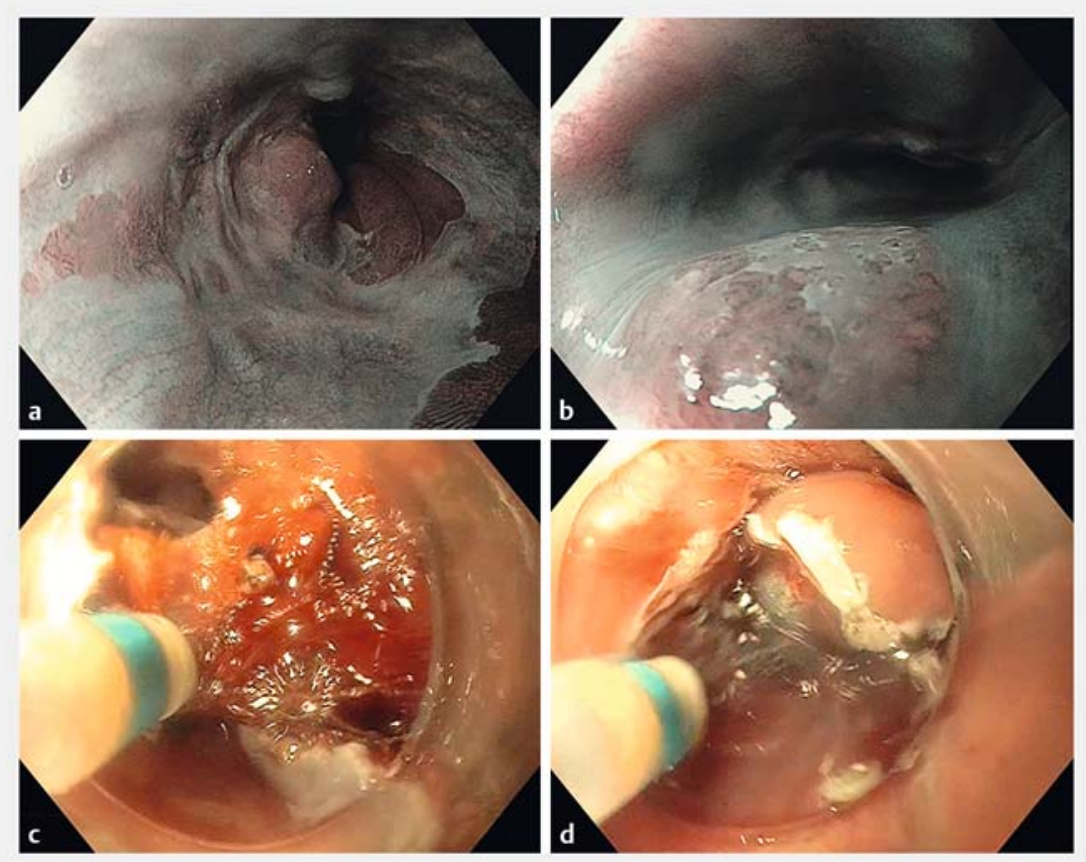

- Fig. 2 Views of the two recurrent lesions found after the initial resection and radiofrequency ablation showing: a a protruded lesion on the anterior wall of esophagus; $\mathbf{b}$ another small visible lesion; $c$ endoscopic submucosal dissection being performed with line traction assistance; $\mathbf{d}$ endoscopic submucosal tunnel dissection being performed.

Although the recurrence rate after curative resection is reported to be low [5], we should not overlook visible lesions during follow-up. ESD is still a preferable and effective management in this situation.

Endoscopy_UCTN_Code_CPL_1AH_2A]

\section{Competing interests}

The authors declare that they have no conflict of interest.

\section{The authors}

Borathchakra Oung ${ }^{1,2}$, Julien Faller ${ }^{3}$, Florence Juget Pietu ${ }^{4}$, Marco Petronio ${ }^{3}$, Mathieu Pioche $^{3}$

1 Faculty of Medicine, University of Health Sciences, Phnom Penh, Cambodia

2 Cambodian Association of Gastrointestinal Endoscopy (CAGE), Cambodia

3 Department of Endoscopy and Gastroenterology, Pavillon L - Edouard Herriot Hospital, Lyon, France

4 Clinique générale Annecy, Annecy, France

\section{Corresponding author}

\section{Mathieu Pioche, MD}

Endoscopy unit - Digestive Disease department, Pavillon L - Edouard Herriot Hospital, 69437 Lyon, France mathieu.pioche@chu-lyon.fr

\section{References}

[1] Weusten B, Bisschops R, Coron E et al. Endoscopic management of Barrett's esophagus: European Society of Gastrointestinal Endoscopy (ESGE) position statement. Endoscopy 2017; 49: 191-198

[2] Pimentel-Nunes P, Dinis-Ribeiro M, Ponchon $T$ et al. Endoscopic submucosal dissection: European society of gastrointestinal endoscopy (ESGE) guideline. Endoscopy 2015; 47: 829-854

[3] Barret M, Cao DT, Beuvon F et al. Endoscopic submucosal dissection for early Barrett's neoplasia. United European Gastroenterol J 2016; 4: 207-215

[4] Jacques ], Legros R, Rivory J et al. The "tunnel + clip" strategy standardised and facilitates oesophageal ESD procedures: a prospective, consecutive bi-centric study. Surg Endosc 2017; 31: 4838-4847

[5] Yang D, Zou F, Xiong S et al. Endoscopic submucosal dissection for early Barrett's neoplasia: a meta-analysis. Gastrointest Endosc 2018; 87: 1383-1393

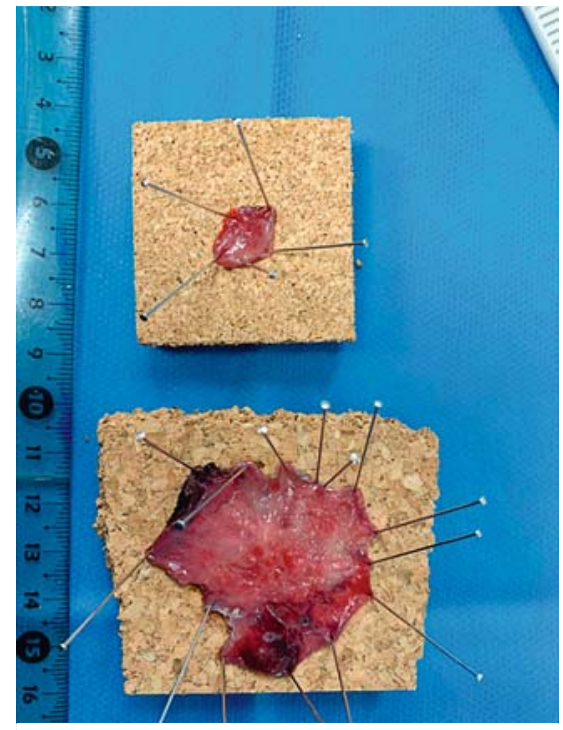

- Fig. 3 Macroscopic appearance of the two resected lesions, measuring $55 \times 40 \mathrm{~mm}$ and $12 \times 10 \mathrm{~mm}$, stretched on cork boards.

Bibliography

Endoscopy 2021; 53: E5-E6

DOI 10.1055/a-1167-8069

ISSN 0013-726X

published online 19.5.2020

(c) 2020. Thieme. All rights reserved.

Georg Thieme Verlag KG, Rüdigerstraße 14, 70469 Stuttgart, Germany

\section{ENDOSCOPY E-VIDEOS}

https://eref.thieme.de/e-videos

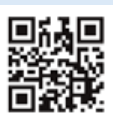

Endoscopy E-Videos is a free access online section, reporting on interesting cases and new techniques in gastroenterological endoscopy. All papers include a high quality video and all contributions are freely accessible online.

This section has its own submission website at https://mc.manuscriptcentral.com/e-videos 